\title{
EL PATRIMONIO TERRITORIAL EN EL PLAN DE ORDENACIÓN DEL TERRITORIO DE ANDALUCÍA: INDEFINICIONES Y DIFICULTADES PARA UN CONOCIMIENTO PRECISO ${ }^{1}$
}

\author{
Gema Florido Trujillo \\ Departamento de Geografía y Ciencias del Territorio. Universidad de Córdoba \\ gema.florido@uco.es
}

\section{RESUMEN}

El Plan de Ordenación del Territorio de Andalucía (POTA) aprobado en 2006 introduce una figura novedosa en la práctica del planeamiento español con la creación del denominado Sistema de Patrimonio Territorial de Andalucía (SPTA) cuya finalidad es la gestión unitaria de los elementos de interés patrimonial, tanto cultural como natural, de la región. No obstante, la identificación en el Plan de los componentes del Sistema no siempre es todo lo precisa y completa que cabría desear. En estas circunstancias, este artículo intenta reconocer, definir y analizar la situación de los elementos y espacios que conforman el SPTA, tratando de delimitar el alcance de éste y de indagar sobre la efectividad de las figuras legales y los instrumentos en los que se apoya.

Palabras clave: Patrimonio Territorial, Ordenación del Territorio, Andalucía.

\section{ABSTRACT}

The Andalusian Territory Organizing Plan (POTA) passed in 2006 introduces a new figure in the practice of the Spanish planning, with the creation of the Andalusian Territorial

Fecha de recepción: enero 2012.

Fecha de aceptación: diciembre 2013.

1 Este trabajo se inscribe en el marco del Proyecto de Investigación CSO2010-19278 (Dinámicas funcionales y ordenación de los espacios del Sistema de Patrimonio Territorial Andaluz: Análisis en Andalucía Occidental), financiado por la Dirección General de Investigación y Gestión del Plan Nacional I+D+i del Ministerio de Ciencia e Innovación del Gobierno de España. 
Heritage System (SPTA), whose aim is the unitary management of the cultural and natural elements of patrimonial interest from the region. However the identification of the system's components in the Plan is not always as precise and complete as it should be. Under these circumstances, this paper wants to recognize, define and analyse the state of the elements and spaces making up the SPTA, and tries to specify its scope, as well as inquire into the effectiveness of the legal figures and the instruments on which it is established.

Key words: Territorial Heritage, Territory Organizing, Andalusia.

\section{INTRODUCCIÓN}

Después de un largo proceso de evolución de contenidos que arranca a mediados del siglo XIX y que aún hoy permanece abierto, recientemente ha tomado forma la noción de «Patrimonio Territorial», un interesante concepto que entiende el espacio geográfico como objeto de interés patrimonial en tanto que resultado de la permanente interacción entre hombre y medio y que insta a observar, interpretar y gestionar de manera unitaria el conjunto de los componentes, tanto naturales como culturales y paisajísticos, que lo conforman. Sobre esta base, el Plan de Ordenación del Territorio de Andalucía (POTA) aprobado en 2006 introduce por primera vez en la práctica del planeamiento español la figura del denominado Sistema de Patrimonio Territorial de Andalucía (SPTA), el cual pretende ser una red coherente cuya finalidad es hacer de dichos recursos un activo para la cohesión y el desarrollo de la región a través de su entendimiento y valorización conjunta.

Es evidente que la novedad del planteamiento, ciertamente avanzado frente a las aproximaciones sectoriales que hasta ahora han constituido la norma, despierta la curiosidad investigadora ya que, pasados algunos años desde la aprobación del Plan, aún son muchas las dudas existentes respecto a la propia configuración del Sistema y a los instrumentos administrativos implementados para su gestión. Más aún cuando no sólo la práctica planificadora sino también las políticas sectoriales de protección patrimonial e incluso los mismos análisis sobre la materia han adolecido tradicionalmente de una más que notable fragmentación.

No obstante, en lo que tiene que ver con el estudio integrado de los elementos patrimoniales, se vienen sucediendo en los últimos años algunas líneas de trabajo de interés. En el ámbito internacional, cabe destacar las actividades del Groupe de géographie et d'histoire des territoires, de l'environnement, des ressources et des sociétes (L'École des Hautes Études en Sciences Sociales- EHESS, París), pionero en este tipo de investigaciones. A escala nacional, los análisis desde una perspectiva geográfica se han centrado fundamentalmente en los estudios del paisaje, entendido éste como resultado de la interacción entre factores naturales e intervenciones humanas. Son de indudable valor las aportaciones, tanto en el plano metodológico como de estudios aplicados a contextos regionales o locales, de diversos grupos de investigación vinculados a distintas universidades (Autónoma de Madrid, Complutense, Girona, Santiago de Compostela, Sevilla, Pablo de Olavide, etc.), así como las aproximaciones más parciales centradas en paisajes de dominante urbano cultural (Complutense, Politécnica de Madrid, Extremadura, etc.) o naturales y rurales (Politécnica de Cataluña, Valladolid, Alicante, León, Cantabria, País Vasco, etc.). Para el caso de Andalucía no puede 
olvidarse la producción del Centro de Estudios Paisaje y Territorio, organismo dependiente de la Consejería de Vivienda y Ordenación del Territorio de la Junta de Andalucía.

En el ámbito específico del patrimonio natural y cultural observado desde una perspectiva globalizadora cabe hacer mención a los trabajos que abordan la construcción histórica del territorio desde una lectura cultural del mismo, así como a los que se interesan por la definición, conocimiento y efectos de la recreación de itinerarios culturales (Ortega, 1998; Florido, 2004; Silva, 2008; entre otros). También han recibido atención la visión geográfica del paisaje y el territorio ofrecida por la geografía tradicional, la literatura de viajes y otras expresiones artísticas, así como la vinculación de los recursos patrimoniales con las posibilidades de fomento turístico en espacios definidos (ej. Herán, 1979; Bosque Maurel, 1995; López Ontiveros, 2001, 2003, 2007; Cortés, 2004; Araque, 2005, Abad, 2006, etc.).

Pero incluso considerando estas aportaciones, hay que constatar que la mayor parte de las líneas de trabajo desarrolladas han estado bastante sectorizadas, de manera que se observa un mayor énfasis en los estudios sobre patrimonio natural y agrario, en especial, referidos a espacios naturales protegidos (vid. Mulero, 2001, 2002, 2005; Pulido, 2005, Molinero, 2007, entre otros) y una presencia más limitada, aunque creciente, de análisis sobre otras manifestaciones del patrimonio histórico-cultural, tradicionalmente relegadas en el contexto de los estudios geográficos. Entre éstas, cabe reseñar líneas de investigación como las dedicadas al análisis de los centros históricos y conjuntos monumentales, la integración de los elementos patrimoniales en el medio rural y las iniciativas para la ordenación y planificación del patrimonio cultural (vid. Caravaca, 1997; Fernández Tabales y Santos, 1999; Fernández Salinas, 2003; Ruiz Ortega, 2004; Florido, 2007; Fernández Cacho, 2008, etc.).

Al margen de estos antecedentes, los estudios específicos sobre el POTA y, muy en particular, sobre el SPTA, son todavía casi inexistentes (haciendo la salvedad de algunos resultados ligados al proyecto de investigación que soporta este trabajo, aún en fase de publicación), de ahí el interés de abordar la cuestión. En este sentido, el estudio que aquí se presenta constituye una primera aproximación al tema centrada en el reconocimiento y definición de los componentes que conforman el Sistema (no siempre definidos con claridad en el propio Plan), tratando de delimitar el alcance del mismo y de indagar sobre la efectividad de las figuras legales y los instrumentos en los que se apoya.

\section{II.METODOLOGÍA}

Desde el punto de vista metodológico, un estudio como éste requiere necesariamente de una revisión sistemática de fuentes de información. A este respecto, para una adecuada contextualización de los datos obtenidos, el paso previo lo constituye el estudio de la bibliografía relacionada con la materia, cuya selección se ha hecho atendiendo al criterio temático de la ordenación del territorio y el patrimonio (tanto natural como cultural y paisajístico), preferentemente en el ámbito de Andalucía. Junto a ello, el trabajo ha partido de la lectura detenida de los documentos de planificación de referencia, principalmente del POTA y de los correspondientes apartados de los Planes Subregionales publicados hasta la fecha, labor que se ha completado con un repaso selectivo, a modo de muestra, de diversos documentos de planeamiento urbanístico. Finalmente, ha sido imprescindible la revisión sistemática de los catálogos y bases de datos de las Consejerías competentes en la materia (Obras Públicas y Vivienda, Medio Ambiente y Cultura) así como de buena parte de la información documental 
generada por dichos organismos, en su mayoría disponible a través de sus respectivas webs. Y, paralelamente, también se ha debido recopilar toda la normativa de ordenación, planeamiento y gestión, estatal y autonómica, de carácter general y sectorial, con afección sobre los elementos patrimoniales.

El establecimiento de las relaciones existentes entre elementos y disposiciones legales, la delimitación de los ámbitos de competencia de los distintos instrumentos y la reflexión sobre la efectividad que en la gestión territorial pueden llegar a tener cada uno de los componentes del SPTA constituyen las líneas básicas de trabajo que articulan este artículo.

\section{CAMBIOS CONCEPTUALES EN LA CONSIDERACIÓN DEL PATRIMONIO: LA MODERNA DEFINICIÓN DEL PATRIMONIO TERRITORIAL}

El II Plan General de Bienes Culturales de Andalucía definía el patrimonio como «el conjunto de elementos naturales y culturales, materiales e inmateriales, heredados de sus antepasados o creados en el presente, en el que los andaluces reconocen sus señas de identidad, y que ha de ser transmitido a las generaciones venideras acrecentado y mejorado». Aunque un enunciado como éste concita hoy un acuerdo general, para llegar a él se ha tenido que recorrer un largo camino que comienza en la segunda mitad del siglo XIX, cuando el concepto de patrimonio, aún con un contenido muy limitado, toma forma como figura jurídica, y se desarrolla a lo largo del XX, a medida que van cambiando las ideas en torno a cuáles deben ser los bienes merecedores de preservación como parte de la herencia común que cada sociedad recibe y tiene el deber de transmitir.

Inicialmente, el objeto de interés patrimonial se centró, de forma casi exclusiva, en elementos y espacios singulares, de valor excepcional y con una fuerte carga estética. En Europa, con siglos de creación artística y cultural, fueron obras de arte y edificios históricos de carácter monumental los que se beneficiaron de las primeras iniciativas de protección legal (Hernández, 2002); en Norteamérica, a falta de una tradición cultural con significado para los nuevos pobladores, las grandezas naturales del territorio se erigieron en principal legado a conservar (Diego y García Codron, 2007). En ambos casos, no obstante, sólo se atribuyó valor patrimonial a elementos naturales o culturales emblemáticos, considerados únicos, cuyo interés devenía fundamentalmente de su atractivo estético y, en su caso, artístico y cuya protección se abordaba de espaldas al entorno que los acogía. Sin embargo, frente a ese planteamiento inicial, restrictivo y elitista, a lo largo del siglo XX el concepto de patrimonio se va transformando y ensanchando de forma progresiva en una triple dirección: temática, cronológica y territorial (Silva, 2009).

En el aspecto temático, el cambio se expresa a través de la adopción de criterios de selección cada vez más amplios. Respecto al patrimonio cultural, el componente histórico que ya estaba presente en las primeras declaraciones adquiere un protagonismo progresivamente mayor, hasta el punto de imponerse sobre los valores artísticos que, sin perder su interés, pasan a un segundo plano. Y ligado a ello, al tiempo que el significado de las obras se va contextualizando vinculándolas al espacio circundante, va creciendo también el número de manifestaciones merecedoras de atención.

Así, abandonado ya a mediados del siglo el concepto de «monumento» a favor de la noción de «bien cultural», gradualmente se van incorporando al ámbito de la protección un 
número creciente de sitios y objetos arqueológicos y paleontológicos, obras arquitectónicas y artísticas, elementos bibliográficos y documentales, creaciones técnicas y científicas, actividades culturales y expresiones etnológicas, en fin, bienes materiales o inmateriales dotados de «valor de civilización» (Comisión Franceschini; tomado de Castillo, 2009: 32). Y ello se traduce desde el punto de vista del tratamiento jurídico en la aparición de figuras de catalogación cada vez más numerosas y pretendidamente más precisas que, por ejemplo, en el caso andaluz, según la vigente Ley 14/2007 de Patrimonio Histórico de Andalucía, se plasma en una detallada clasificación del Patrimonio Inmueble, el Patrimonio Mueble y los Patrimonios especiales (Arqueológico, Etnológico, Industrial, Documental y Bibliográfico).

En lo que atañe al patrimonio natural, el camino seguido marca una trayectoria similar, como muestra el ordenamiento jurídico que, al igual que en otros países de nuestro entorno, se va promulgando en España (vid. Florido y Lozano, 2005). Si en las primeras declaraciones la espectacularidad del paisaje y los valores para el esparcimiento son los criterios decisivos a la hora de calificar espacios naturales, pronto se incorporarán a la selección razones «de interés científico, artístico, histórico o legendario»-como, por ejemplo, se cita en el Real Decreto de 20 de Julio de 1929 de reorganización de la Junta Central de Parques Nacionales de España-. Con el paso del tiempo, éstas irán posibilitando la progresiva protección de áreas relevantes por su riqueza botánica, faunística, geológica, geomorfológica y paleontológica (Ley de 2 de mayo de 1975 de Espacios Naturales Protegidos), para llegar al momento actual en el que, junto con las anteriores, se tienen en cuenta razones de índole educativa, cultural y social -como recogen varias de las figuras de protección establecidas por la Ley 42/2007 del Patrimonio Natural y la Biodiversidad-.

A los cambios mencionados no ha sido ajena la ampliación del marco temporal respecto al cual se ha venido definiendo el interés de los bienes patrimoniales. Inicialmente la edad del elemento era criterio decisivo, hasta el punto de no ser tomadas en consideración más que manifestaciones culturales de origen remoto -sirva de ejemplo la Ley de Excavaciones Arqueológicas de 1911 según la cual las «antigüedades» que eran su objeto de atención comprendían «todas las obras de arte y productos industriales pertenecientes a las edades Prehistórica, Antigua y Media» (art. 2); o la declaración de algunos de los primeros enclaves protegidos en España, como el Parque Nacional de la Montaña de Covadonga (1918) o el Sitio Natural del Monte de San Juan de la Peña (1920), ligados desde el punto de vista simbólico a acontecimientos históricos o legendarios acaecidos en el medievo-. Sin embargo, poco a poco dicha restricción se iría relajando y así, ya en la Ley de 13 de Mayo de 1933 de Patrimonio Artístico Nacional se afirma que forman parte de él «cuantos inmuebles y objetos muebles de interés artístico, arqueológico, paleontológico o histórico haya en España de antigüedad no menor de un siglo; también aquellos que sin esta antigüedad tengan un valor artístico o histórico indiscutible, exceptuando, naturalmente, las obras de autores contemporáneos» (art. 5). Hoy, también la contemporaneidad ha dejado de ser un factor excluyente gracias a lo cual ya no se cuestiona la necesidad de protección de manifestaciones culturales recientes en el tiempo e incluso aún funcionalmente activas (léase, por ejemplo, espacios y elementos del patrimonio industrial, expresiones diversas del patrimonio etnológico o, particularidades lingüísticas, tal como recoge la Ley 14/2007), componentes todos ellos de pleno derecho de inventarios y catálogos, aunque todavía con una presencia muy limitada. 
Por otra parte, el progresivo enriquecimiento del concepto de patrimonio irá dando lugar a la incorporación de una dimensión territorial que acabará siendo clave en su entendimiento, tratamiento y gestión. Como antes se apuntaba, los primeros pasos en esta dirección se dan con el reconocimiento del significado que el medio físico y social tienen para la comprensión de los monumentos que, más allá de su propia singularidad, sólo encuentran pleno sentido vinculados al contexto histórico, ambiental y funcional en el que se insertan. De la valoración y salvaguarda del entorno de los bienes se pasará más adelante a la apreciación de los conjuntos urbanos, en los cuales se localizan buena parte de los bienes protegidos y que se convertirán desde mediados del pasado siglo en espacios de atención y actuación preferente. Y más cercana en el tiempo es la confluencia entre el patrimonio natural y el patrimonio cultural, durante décadas observados y gestionados de forma independiente y sólo en fechas más recientes contemplados de manera conjunta.

Alcanzado este punto no podemos decir que la tradicional división entre patrimonio natural y patrimonio cultural se haya superado por completo. De hecho, en la práctica aún persiste la acostumbrada distinción entre ambos, arraigada en más de un siglo de visión sectorial y de gestión fragmentada (Ortega, 2004). Pero también es cierto que en los últimos años cada vez adquieren más significación las aproximaciones integradas en las cuales el territorio, el espacio geográfico humanizado, se erige en referente indispensable para la interpretación y la revalorización del patrimonio. Y no sólo eso. También el territorio mismo se convierte en objeto de interés patrimonial en cuanto que resultado de la histórica relación dialéctica entre hombre y medio. Esta relación ha sido cambiante, dependiendo tanto de las posibilidades reales de modificación como de las necesidades y de la valoración que de su entorno ha tenido cada sociedad, pero en todos los casos ha provocado intervenciones sucesivas, e interrelacionadas que han construido un espacio de honda raigambre cultural, el cual, a pesar de su complejidad, es susceptible de ser analizado y valorado desde premisas equivalentes a las aplicadas a los demás bienes culturales (Florido, 2004).

Es así como se llega a la reciente aparición del concepto de «Patrimonio Territorial», una sugerente noción cada vez más presente, explícita o implícitamente, en los estudios sobre la materia (vid., entre otros, Troitiño, 1998; Ortega, 1998 y 2004;; Florido, 2004; Fernández Salinas y Caravaca, 2004; Feria, 2005; Silva y Fernández, 2008; Silva, 2008 y 2009; Bellido, 2009; Cañizares, 2009; Castillo, 2009; López y Cifuentes, 2009; Feria, 2010; Mata, 2010; etc.) y que en la práctica se expresa en una doble perspectiva.

Por una parte, considerando el territorio como escenario de confluencia de bienes de distinta naturaleza en el cual éstos se entienden y cobran pleno sentido a través del sistema de interrelaciones e influencias recíprocas establecidas a lo largo de la historia. Es de esta manera como se concibe, por ejemplo, el SPTA establecido en el POTA que observa el territorio como un mosaico de espacios y elementos protegidos, articulados física y funcionalmente a través de diversos ejes de comunicación que los interconectan entre sí. Con una estructura en red a escala regional, el Plan pretende que dicho sistema pueda ser gestionado de forma unitaria mediante instrumentos de planificación cuyo referente serán ámbitos que reflejen las diferentes expresiones de las culturas territoriales presentes en Andalucía y que 
sirvan como marco para las actuaciones de protección, difusión y puesta en valor que se traten de implementar (Junta de Andalucía, 2006).

Por otra parte, en su segunda acepción, el Patrimonio Territorial toma forma desde el entendimiento del espacio geográfico como «lugar», producto social singular, construcción humana elaborada a partir del sustrato físico original a través de un largo y continuo proceso histórico de transformación y evolución diferenciada y cargada de significados culturales y simbólicos que, dentro de su marco de vida habitual, son percibidos por la propia población como expresión de la memoria colectiva e interiorizados, sentidos y valorados como seña de identidad (Ortega, 1998). Es este contenido el que se plasma en la formalización jurídica de la figura de «Zona Patrimonial» incluida en la Ley 14/2007 de Patrimonio Histórico de Andalucía, según el enunciado del propio texto, con el objeto de afrontar la protección del patrimonio desde un enfoque territorial, para lo cual delimita como tal «espacios que constituyen un conjunto patrimonial, diverso y complementario, integrado por bienes diacrónicos representativos de la evolución humana, que poseen un valor de uso y disfrute para la colectividad y, en su caso, valores paisajísticos y ambientales» (art. 26). Y en una línea similar, aunque poniendo el acento en el componente visual del espacio geográfico, se observa el paisaje, entendiendo por tal «cualquier parte del territorio tal y como es percibida por las poblaciones, cuyo carácter resulta de la acción de los factores naturales y humanos y sus interrelaciones» (según la definición del Convenio Europeo del Paisaje). Así es recogido en la Ley 42/2007 del Patrimonio Natural y la Biodiversidad de España cuya figura de «Paisajes Protegidos» pretende, entre otras, «la preservación de la interacción armoniosa entre la naturaleza y la cultura» (art. 34). En Andalucía, el POTA hace de él un elemento clave en la estrategia de conservación y gestión de los recursos patrimoniales e incorpora su gestión al SPTA con el objetivo de favorecer su mejor conocimiento, fomentar el aprecio de sus valores y reforzar el compromiso intergeneracional de la sociedad con su mantenimiento como patrimonio colectivo.

\section{EL SISTEMA DEL PATRIMONIO TERRITORIAL EN EL POTA: CONFIGURACIÓN Y SIGNIFI- CADO}

«Andalucía es, sin duda, una de las regiones europeas con mayor riqueza de valores y recursos patrimoniales, culturales, ambientales y paisajísticos, resultado de un medio natural particularmente diverso y de una prolongada historia de colonización humana, la cual ha dejado huellas de múltiples culturas» (Junta de Andalucía, 2006: 109). Esta afirmación, junto con la constatación de la persistencia de planteamientos excesivamente parciales y fragmentarios en el entendimiento del patrimonio y de su, hasta ahora, insuficiente utilización como recurso para el desarrollo regional son los argumentos iniciales del POTA para el desarrollo de una innovadora figura incorporada por primera vez a la práctica planificadora dentro del modelo organizativo de la región, el llamado «Sistema del Patrimonio Territorial de Andalucía».

En este sentido, el Plan define su modelo en base a tres grandes sistemas (Sistema de Ciudades, de Articulación Territorial y de Protección del Territorio), estableciendo dentro de este último, junto al Sistema de Prevención de Riesgos, el SPTA, una red coherente que 
integra todos los espacios y bienes con relevancia patrimonial existentes en la Comunidad Autónoma. Su objetivo no sólo es superar la tradicional visión de elementos aislados y yuxtapuestos, sino, sobre todo, asegurar su entendimiento, gestión y valorización desde una perspectiva conjunta y unitaria (Zoido, 2011) y reforzar el aprovechamiento de las sinergias de desarrollo local y regional que se puedan generar.

El nuevo planteamiento conceptual, consecuente con la lógica de comprensión integradora del territorio con la que el POTA trata de reforzar la cohesión interior de la región, se apoya desde el punto de vista operativo en tres elementos esenciales:

1. Unos referentes territoriales para la planificación y gestión del patrimonio, concretados a través de la delimitación de ámbitos espaciales a distintas escalas, que son: los «dominios territoriales» (el marco más genérico, conformado por espacios con valores ecológicos, culturales y paisajísticos relativamente homogéneos); las «unidades territoriales» (áreas con sistemas de poblamiento desarrollados sobre una base histórica, cultural y ecológica común); las «redes urbanas de interés patrimonial» (susceptibles de desarrollar procesos de cooperación para la gestión de los bienes culturales); y los «ámbitos con especiales valores naturales y paisajísticos» con sus correspondientes redes de «asentamientos urbanos de acceso» (entre los cuales se establecen planes coordinados para la gestión de los espacios naturales).

2. Unas estrategias de planificación y gestión integrada del Patrimonio Territorial establecidas a través de Programas Coordinados para cada uno de los ámbitos escalares señalados, en cuya elaboración participan las diferentes instancias administrativas del gobierno regional. Con ellos se pretende concertar las políticas patrimoniales existentes (tanto ecológicas, como culturales y paisajísticas) con las urbanísticas, de ordenación del territorio y de desarrollo económico, en particular las relacionadas con la promoción turística de los bienes patrimoniales.

3. Un Sistema de Información de espacios y bienes catalogados del Patrimonio Territorial, gestionado conjuntamente por las Consejerías de Obras Públicas, Medio Ambiente y Cultura y en el que se incluyan tanto los espacios y elementos que ya gozan de protección legal como los que progresivamente se vayan incorporando a catálogos e inventarios, los cuales, hasta el momento, vienen siendo regulados por normativas heterogéneas y tratados a través de una amplia panoplia de instrumentos con muy escasa imbricación entre ellos (Mulero et alii, 2011).

Es precisamente en este último apartado en el que ahora queremos centrar la atención. Aunque ya la Ley 1/1994 de Ordenación del Territorio de Andalucía establecía la creación de un Sistema de Información Territorial que sirviese como instrumento de apoyo para la toma de decisiones en esta materia y que incluyese todos los datos necesarios para la interpretación y diagnóstico de los procesos territoriales, el banco de datos desarrollado hasta la fecha por el Instituto de Estadística y Cartografía de Andalucía no incluye ningún apartado relativo a la cuestión que aquí nos ocupa. Por su parte, a pesar de que ya ha pasado más de un quinquenio desde la aprobación del POTA, el Sistema de Información que allí se preveía tampoco se ha puesto en marcha, de modo que seguimos sin contar con una plataforma unificada y compartida a través de la que poder identificar y tratar conjuntamente todos los componentes del SPTA. 


\section{LA FRAGMENTACIÓN DE LAS FUENTES Y LA FALTA DE CATÁLOGOS INTEGRADOS}

Como decimos, el que debía ser el instrumento básico para la gestión e información pública sobre Patrimonio Territorial en Andalucía sigue sin implementarse y, al menos según los datos que proporciona la web de la Consejería de Obras Públicas y Vivienda, no se ha avanzado de forma clara en esta dirección, si bien, aunque de manera no coordinada entre ellos, los organismos competentes han ido poniendo en marcha iniciativas propias que suponen pasos adelante.

La Consejería de Medio Ambiente ha desarrollado la Red de Información Ambiental de Andalucía (REDIAM) cuya finalidad es integrar todos los datos disponibles sobre la materia en Andalucía. Con antecedentes en el Sistema de Información geográfico-ambiental, que desde 1984 se encargó de recoger, coordinar y estructurar los datos disponibles sobre el estado del medio ambiente y los recursos naturales de la región, la REDIAM se nutre de los informes proporcionados, gracias a diversos convenios de colaboración, por universidades, centros de investigación, empresas, organizaciones sociales, etc. A partir de ahí se elaboran bases de datos con criterios técnicos comunes que a su vez se ponen a disposición de los centros asociados para permitir un uso compartido y posibilitar la planificación y gestión coordinada de sus actuaciones ambientales.

En lo que atañe al SPTA, dentro del Catálogo Estructurado por materias con el que cuenta el sistema, se establece un apartado específico sobre Patrimonio Natural a través del cual se da noticia de bienes patrimoniales como los Espacios Naturales Protegidos (ENP), los montes públicos, las vías pecuarias, etc. Pero además, la REDIAM desarrolla una serie de subsistemas por ámbitos temáticos en cada uno de los cuales se recopila la información específica, se realiza la revisión, corrección, depuración y análisis de los datos y se ofrecen todos los productos derivados de la explotación de los mismos (informes, inventarios, cartografía, ortofotografía, etc.). En un estado de desarrollo muy avanzado, actualmente se cuenta con siete subsistemas de información plenamente operativos (Climatología Ambiental, Biodiversidad, Geodiversidad, Humedales, Aguas, Litoral y Medio Marino, y Paisaje) muchos de ellos de singular interés para el entendimiento y la gestión del SPTA. No obstante, aún está en fase de proyecto el correspondiente a la Red de Espacios Naturales Protegidos de Andalucía (RENPA), fundamental a los efectos que nos ocupan.

En la Consejería de Cultura también está progresando la puesta en marcha de un sistema integrado para la gestión de los bienes culturales pero todavía se está en una etapa más atrasada. En este caso, el proceso comenzó con la creación en 1991 del Sistema de Información del Patrimonio Histórico de Andalucía (SIPHA), un registro único implantado en la Dirección General de Bienes Culturales y las Delegaciones Provinciales al que se fueron incorporando las preexistentes bases de datos sobre Ciudades Históricas, Patrimonio Inmueble, Actividades Arqueológicas y Bienes Muebles. Con un claro entendimiento del componente territorial del patrimonio, pronto comenzó a incorporar la tecnología SIG a la información sobre los bienes culturales, de modo que fue posible ir avanzando en su cartografía. En coordinación con la Consejería de Obras Públicas y Vivienda, desde 2001-2002 se desarrollaron proyectos como el de creación de la base de datos de ciudades históricas de Andalucía (Muñoz, 2006; Ladrón de Guevara, 2007). Hoy el SIPHA relaciona las distintas bases de datos entre sí y con un visualizador cartográfico y hace posibles, entre otras, funciones de 
consulta tanto genérica como específica. No obstante, a pesar del avance que supuso este instrumento, la Consejería seguía disponiendo sólo de sistemas sectoriales de documentación, de ahí que en 2004 se plantease el proyecto de creación de una nueva herramienta, el llamado Sistema de Gestión del Patrimonio Cultural: MOSAICO, con el que abordar de forma unificada las actividades necesarias para la planificación y administración de los bienes culturales. La aplicación, cuyo interés en relación con el SPTA parece evidente, sigue todavía en fase de implementación de modo que aún no es posible su utilización para fines como los contemplados en el POTA.

Por su parte, la Consejería de Obras Públicas y Vivienda también facilita información sobre Ordenación del Territorio y Urbanismo a través de su página web, dando acceso a los instrumentos de carácter técnico y normativo de ordenación de usos del suelo. No obstante, la consulta de los contenidos referentes a los elementos patrimoniales se hace más complicada ya que el planeamiento urbanístico precisa de la revisión de los documentos de cada uno de los municipios los cuales, dadas sus fechas de elaboración, no incluyen este tipo de información de manera sistemática.

Al margen de las fuentes a las que nos venimos refiriendo, cabe añadir que en la ordenación territorial el planeamiento no ha abordado la creación de catálogos completos en ninguno de los ámbitos de referencia delimitados por el POTA sobre los cuales poder apoyar las estrategias coordinadas de intervención a las que el documento aspira. Ni tampoco los instrumentos de escala subregional a través de los que desarrollar las directrices generales llevan a cabo una recopilación exhaustiva de los bienes patrimoniales radicados en sus términos, aunque sí que, en distinta medida según el caso, identifican los componentes básicos del sistema y señalan la necesidad de reforzar su protección y puesta en valor (Mulero et alii, 2011).

$\mathrm{Si}$ a todo ello unimos la insuficiente definición que el mismo POTA realiza de algunos de los componentes del SPTA, la diferente cobertura jurídica de la que gozan los distintos elementos contemplados en el Plan a tenor de las leyes que les afectan, y las dispares consecuencias que hasta ahora se han derivado de las declaraciones realizadas se entiende la dificultad para delimitar con precisión el alcance del Sistema y para desarrollar las estrategias de gestión conjunta planteadas así como las consiguientes dudas sobre la efectividad real que las propuestas puedan llegar a tener.

\section{EL CARÁCTER DE LOS COMPONENTES DEL SPTA: PROBLEMAS DE DEFINICIÓN Y DELI- MITACIÓN}

Antes apuntábamos que el POTA determina cuál es el Patrimonio Territorial de la región con un doble criterio. Por una parte, observa el conjunto de elementos, bienes y espacios con valor patrimonial que confluyen sobre el territorio andaluz (que son los que en el Plan expresamente se consideran «componentes del SPTA»), cuya interrelación permite entender el proceso de ocupación del espacio geográfico. Por otra parte, desde una perspectiva de conjunto, presta una atención singular a los paisajes «desde su entendimiento como legado histórico e identidad colectiva» $\mathrm{y}$, en este sentido, «como elemento clave en la estrategia de conservación y gestión de los recursos patrimoniales» (Junta de Andalucía, 2006: 116). 
Cuadro 1

COMPONENTES DEL SPTA

\begin{tabular}{|c|l|}
\hline \multirow{5}{*}{$\begin{array}{c}\text { Componentes de carácter } \\
\text { natural }\end{array}$} & $\begin{array}{l}\text { Espacios naturales y bienes protegidos por instrumentos } \\
\text { internacionales y LICs }\end{array}$ \\
\cline { 2 - 3 } & $\begin{array}{l}\text { Red de Espacios Naturales Protegidos de Andalucía } \\
\text { Espacios incluidos en el Catálogo de Espacios y Bienes protegidos } \\
\text { de los Planes Especiales de Protección del Medio Físico de ámbito } \\
\text { provincial o, en su caso, los suelos no urbanizables calificados de } \\
\text { especial protección por el planeamiento territorial o urbanístico }\end{array}$ \\
\cline { 2 - 3 } Componentes de carácter & $\begin{array}{l}\text { Zonas que constituyen el dominio público hidráulico marítimo } \\
\text { terrestre }\end{array}$ \\
\cline { 2 - 2 } cultural & Vías pecuarias y otros «caminos naturales» \\
\cline { 2 - 2 } & Inventarios de georrecursos y de humedales \\
\hline & $\begin{array}{l}\text { Ciudades históricas protegidas como Conjuntos Históricos } \\
\text { Otras ciudades históricas no protegidas pero equivalentes en } \\
\text { valores a los Conjuntos Históricos }\end{array}$ \\
\cline { 2 - 2 } $\begin{array}{l}\text { Patrimonio inmueble con categoría BIC o inscrito en el Catálogo } \\
\text { General del Patrimonio Histórico de Andalucía }\end{array}$ \\
\cline { 2 - 2 } & $\begin{array}{l}\text { Otros yacimientos arqueológicos y elementos del patrimonio } \\
\text { cultural }\end{array}$ \\
\hline
\end{tabular}

Fuente: Junta de Andalucía, 2006. Elaboración propia.

Figura 1

GRANDES COMPONENTES DEL SISTEMA DE PATRIMONIO TERRITORIAL DE ANDALUCÍA

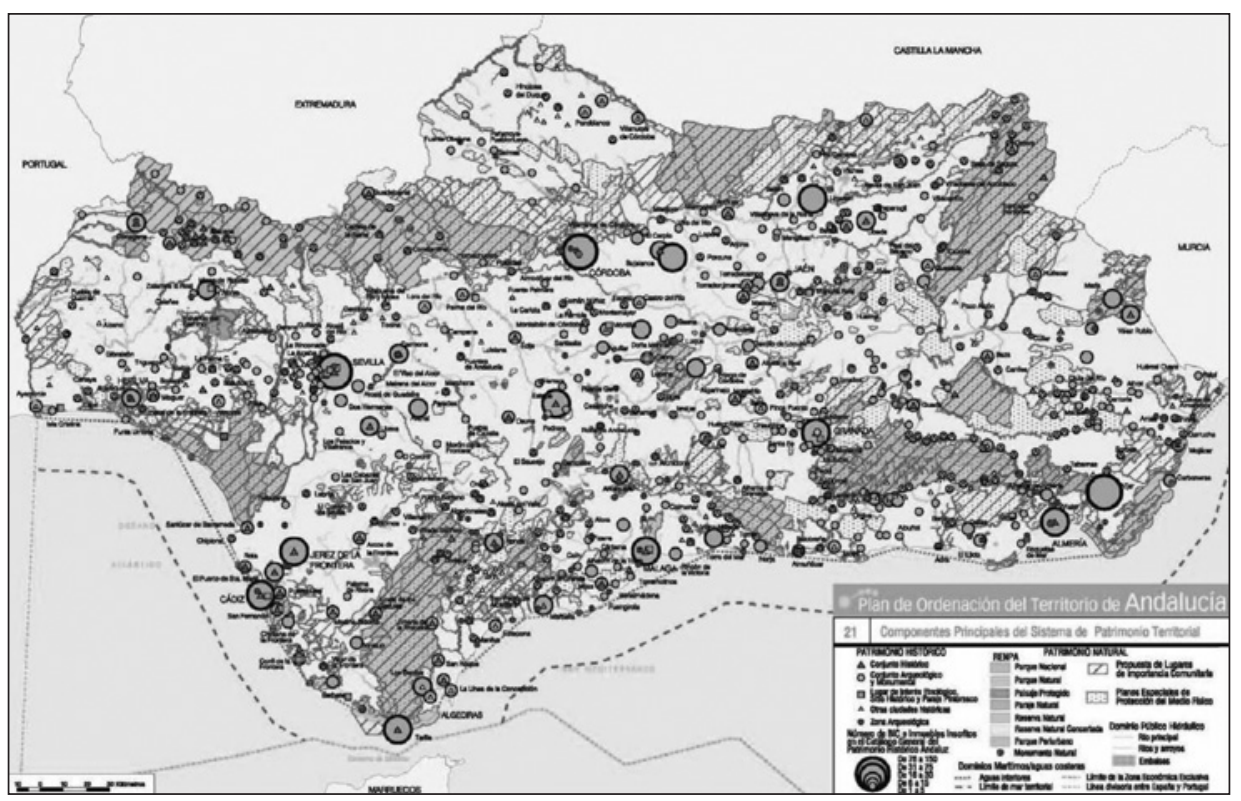

Fuente: Junta de Andalucía, 2006. 
Centrando la atención en el primer método de aproximación, como no podía ser de otro modo si se tiene en cuenta la progresiva ampliación que el concepto de bien patrimonial ha ido experimentando en los últimos tiempos, hay que decir que la lista de componentes que el Sistema contempla es extensa y variada. No por ello dejan de echarse en falta elementos o espacios reseñables sobre los que algunos autores llaman la atención pero cuya aceptación social todavía no está plenamente conseguida y, en consecuencia, tampoco su integración en los repertorios de bienes a proteger elaborados hasta la fecha -léase el caso de los espacios de la agricultura (Silva, 2008) o de determinados bienes del patrimonio etnológico, alejados de los tradicionales patrones del arte culto (Agudo, 2009)-. Aun así, dada la riqueza patrimonial de Andalucía, son muchos los bienes a considerar (vid. Cuadro 1 y Fig. 1), aunque en el POTA su identificación no siempre es todo lo precisa y completa que cabría desear.

\subsection{Los componentes de carácter natural}

La relación de componentes del Sistema que el POTA establece, comienza haciendo referencia a los recursos y áreas naturales de valor patrimonial, dentro de las cuales queda enmarcado un vasto territorio tutelado por normativas de distinto carácter.

\subsubsection{Espacios naturales y bienes culturales protegidos por instrumentos internacionales y LICs}

Éste grupo de espacios son áreas designadas en razón de los Convenios, Acuerdos y Directivas suscritas por el Estado español y que abarcan un amplio repertorio de figuras de calificación (Florido y Lozano, 2005), de las cuales en el SPTA se hace mención a las siguientes:

- Reservas de la Biosfera: esta figura se establece a partir de 1971 dentro del Programa «Hombre y Biosfera» (MaB) que es un instrumento mediante el cual la UNESCO trata de abordar la problemática del desarrollo y el medio ambiente desde planteamientos de equilibrio e integración y que en la actualidad se erige en símbolo internacional de la conservación y la sostenibilidad. En el caso de Andalucía, según datos de la Consejería de Medio Ambiente (que utilizamos de fuente para todo este apartado), integran la red ocho Reservas situadas en distintos ámbitos de la región a las que hay que unir la Intercontinental del Mediterráneo entre España y Marruecos, abarcando en total una extensión de casi un millón y medio de hectáreas.

- Sitios Patrimonio de la Humanidad: establecidos a partir de las conclusiones de la Convención sobre la Protección del Patrimonio Mundial, Cultural y Natural asumidas en la XVII Reunión de la Conferencia General de la UNESCO de 1972, los espacios que son merecedores de tal distinción por su excepcionalidad se integran en el Listado del Patrimonio de la Humanidad, al cual, a fecha de Agosto de 2011, Andalucía aporta un total de cinco espacios, siendo el Parque Nacional de Doñana (distinguido en 1994) el único de carácter natural.

- Humedales de la Convención Ramsar: en vigor desde 1975, el tratado intergubernamental sobre humedales de importancia internacional ha permitido la creación de una amplia red de ecosistemas húmedos en la que Andalucía participa a partir de 1982. De entonces a ahora se han sumado en la región un total de 25 espacios, con una superficie de más de 
143.000 ha en las que está representada la gran diversidad de tipos ecológicos aquí existentes.

- Zonas Especialmente Protegidas de Importancia para el Mediterráneo (ZEPIM): resultado de la puesta en marcha de los acuerdos recogidos en el Protocolo de Áreas Especialmente Protegidas y Diversidad Biológica del Mediterráneo (1999) anexo al Convenio de Barcelona de 1976, la ZEPIM constituye una red de espacios marinos y costeros destacables por sus valores ecológicos y representativos de los hábitats del Mediterráneo conformada hasta la fecha por catorce áreas. De ellas, cuatro se encuentran en Andalucía, siendo la región que acapara mayor número de espacios reconocidos.

- Lugares de Importancia Comunitaria (LICs) de la región biogeográfica mediterránea: como es sabido, las propuestas de LICs realizadas por Estados miembros de la Unión Europea tienen por objeto la creación de un sistema de Zonas de Especial Conservación (ZECs) con el que se garantice la preservación de su biodiversidad. El conjunto de ZECs conforman la Red Natura 2000, dentro de la cual Andalucía es parte de la región biogeográfica mediterránea a la que proporciona 195 espacios con una extensión total en torno a las 2.625.000 ha. Y, aunque el POTA no los menciona de forma expresa en este apartado de instrumentos de protección internacionales, por estar igualmente integradas en la Red Natura, a ellos habría que unir 63 Zonas de Especial Protección para las Aves (ZEPAs) (1.644.110 ha) establecidas a partir de la Directiva Aves de 1979 y que, por otra parte, sí que se contemplan con carácter genérico dentro de la Red de ENP de Andalucía (RENPA) de la que se hablará a continuación.

Aunque también incluidos en la RENPA, tampoco alude el POTA dentro de los espacios de protección internacional a los distinguidos con el Diploma Europeo, figura creada en 1965 para reconocer ámbitos excepcionales a escala europea y de la que desde 1985 goza el Parque Nacional de Doñana (Junta de Andalucía, 2006). Y lo mismo ocurre con los Geoparques, territorios con un patrimonio geológico notable, que llevan a cabo proyectos de desarrollo basados en su promoción turística y que se organizan desde 2000 dentro de la Red de Geoparques Europeos, una iniciativa que la UNESCO auspició e hizo extensiva a todo el mundo en 2004. Andalucía incorporó a dicha Red dos geoparques en 2006 (Cabo de Gata-Níjar y Sierras Subbéticas), a los que ha sumado en septiembre de 2011 un tercero (Parque Natural de la Sierra Norte de Sevilla), estando a la espera de resolución la candidatura de la Cuenca Minera de Río Tinto.

Por último, hay que tener en cuenta que, aunque el POTA no lo menciona al hablar de los componentes de SPTA, cuando define la configuración que debe tener el Sistema de Información de espacios y bienes catalogados del Patrimonio Territorial establece la necesidad de que se añadan a dicho instrumento «todos aquellos nuevos espacios y elementos que se incorporen, con posterioridad al Plan, a algunos de los catálogos de protección por los organismos competentes en la gestión de cada una de las figuras de protección» (POTA, 2006: 116). Lógicamente, dicha adición no tiene otra finalidad que la de ir sumando progresivamente al STPA estos bienes. Pues bien, en relación con los instrumentos de carácter internacional y aunque de momento esta figura no se ha hecho efectiva en Andalucía, cabe entender que por su posible identificación a futuro también deberían tenerse en consideración las Reservas Biogenéticas del Consejo de Europa, designación de los hábitats naturales especialmente valiosos para la conservación de la naturaleza en Europa expresamente recogida en la Ley 42/2007 del Patrimonio Natural y de la Biodiversidad. 
En cuanto a la gestión, la situación de estos espacios es dispar, unas veces porque las figuras, por su novedad, no quedan definidas de forma nítida en los documentos legislativos encargados de su regulación; otras, porque la propia dinámica de desarrollo de los instrumentos no sigue los ritmos necesarios para una acción efectiva. Sirva de ejemplo el caso de los espacios incluidos en la Red Natura 2000, como se ha dicho, de una enorme extensión en la región. Respecto a ellos, la Ley 42/2007 del Patrimonio Natural y de la Biodiversidad establece la obligatoriedad de elaborar directrices de conservación que, sin precisar competencias, encarga al Ministerio de Medio Ambiente con la participación de las Comunidades Autónomas. Sin embargo, hasta el momento (y a pesar de que debían estar elaborados para mediados de 2012), ni uno solo de los LICs o ZEPAs declarados en Andalucía ha aprobado planes específicos de gestión, lo cual resta efectividad real a las declaraciones y, en buena lógica, condiciona seriamente su operatividad dentro del SPTA.

\subsubsection{La Red de Espacios Naturales Protegidos de Andalucía}

Un segundo grupo de componentes naturales a los que el POTA alude como conformadores del SPTA son todos los integrados en la RENPA, red desarrollada a partir de lo dispuesto en la Ley 2/1989 de Inventario de Espacios Naturales Protegidos de Andalucía. Según lo que se establece en el artículo 1 del Decreto 95/2003 por el que se regula la RENPA y su Registro, forman parte de la misma «todas las áreas amparadas por normativa tanto autonómica como estatal y comunitaria o por convenios y normativas internacionales», siendo en la actualidad un total de 244 espacios que por su extensión, 2,8 millones de ha, ocupan el 30,5\% de la superficie regional.

Con posibilidad de acumular más de una designación o figura de protección, se integran en la RENPA tanto las áreas a las que se ha hecho mención en el apartado anterior como los ENP de Andalucía los cuales, en sentido estricto, son las Zonas de Importancia Comunitaria correspondientes a las áreas andaluzas integradas en la Red Natura 2000 de las que ya se ha hablado (ZEPAs y ZECs), así como los espacios directamente protegidos por la legislación propia. Puesto que cuando en Andalucía se promulgó la Ley de Inventario el código vigente a escala nacional era la Ley 4/1989 de Conservación de los Espacios Naturales y de la Flora y Fauna Silvestre, las categorías de protección establecidas por el ordenamiento autonómico contemplan lo que allí se recogía junto con las figuras que los legisladores autonómicos tuvieron a bien añadir en virtud de las posibilidades que el mismo texto legal les otorgaba, a las cuales se ha sumado con posterioridad la de Monumento Natural (establecida mediante el Decreto 255/1999). Así, los ENP andaluces, cuyo territorio abarca aproximadamente 1,8 millones de ha, más del $20 \%$ de la superficie de la Comunidad Autónoma, son en la actualidad los siguientes: 2 Parques Nacionales; 24 Parques Naturales; 21 Parques Periurbanos, 32 Parajes Naturales; 2 Paisajes Protegidos; 40 Monumentos Naturales; 28 Reservas Naturales y 5 Reservas Naturales Concertadas.

Pero si éstos son los componentes del SPTA que aporta la RENPA, con la misma filosofía que en el caso anterior de considerar las modificaciones producidas con posterioridad a la redacción del POTA y, sobre todo, las indicaciones del Decreto 95/2003, a futuro también habrá que considerar espacios calificados como Áreas Marinas Protegidas, figura incorporada por la Ley 42/2007 pero que aún no ha tenido plasmación específica en el ordenamiento andaluz. 
La regulación de este tipo de espacios a través de la legislación sectorial es precisa. Pero no por ello siempre ha sido adecuada su efectividad desde el punto de vista de la ordenación territorial, en particular en lo que atañe a su pretendida función como instrumento de desarrollo local. En este sentido, son numerosos los trabajos que hasta ahora han puesto de manifiesto el habitual desencuentro existente entre la conservación y uso público de los espacios protegidos y la planificación de actividades y aprovechamientos permitidos a la población local, de modo que, con frecuencia, las declaraciones han chocado con los intereses particulares, han devenido en una falta de efectividad real para lograr el progreso de las zonas afectadas y han provocado la desafección de los agentes sociales (vid. Mulero, 2005; Molinero, 2007; Gómez, 2011). Si, con estos antecedentes, se consideran sus posibilidades dentro del SPTA tampoco parece que, en modo alguno, puedan quedar garantizados los objetivos que éste persigue.

\subsubsection{Espacios incluidos en el Catálogo de Espacios y Bienes Protegidos de los Planes Especiales de Protección del Medio Físico de ámbito provincial o, en su caso, los suelos no urbanizables calificados de especial protección por el planeamiento territorial o urbanístico.}

Apoyándose en los preceptos de la Ley 19/1975 de reforma de la Ley sobre Régimen del Suelo y Ordenación Urbana relativos a la preservación del medio ambiente, conservación de la naturaleza y defensa del paisaje, los Planes Especiales de Protección del Medio Físico (PEPMF) se llevaron a cabo en Andalucía entre 1982 y 1986, un momento en que todavía eran muy escasas las iniciativas de política ambiental y la región apenas contaba con instrumentos de ordenación de los espacios naturales. Cubriendo íntegramente el ámbito andaluz, los ocho catálogos provinciales establecieron una amplísima selección de espacios de interés natural (410 áreas, con unos 2.300.000 ha de extensión, el 27,3\% del territorio andaluz), lo que representó una acción de recopilación e inventario muy superior a todo lo hecho previamente (Zoido, 2002) y estableció lo que podrían considerarse las bases para la definición de la red de ENP con valores de ordenación territorial que terminaría consolidándose muchos años después a través del POTA. Por su parte, la misma Ley establecía la posibilidad de que el planeamiento municipal delimitase en su término suelos no urbanizables de especial protección «en razón de su excepcional valor agrícola, forestal o ganadero, de las posibilidades de explotación de sus recursos naturales, de sus valores paisajísticos, históricos o culturales o para la defensa de la fauna, la flora o el equilibrio ecológico» (art. 75), los cuales completarían el repertorio de lugares de interés singular.

En la actualidad, la mayor parte de las áreas delimitadas en estos instrumentos se encuentran amparadas por las distintas figuras de calificación a las que hasta aquí se ha hecho referencia. Aunque la Ley 1/1989 de Inventario de Espacios Protegidos de Andalucía seleccionó inicialmente un menor número de lugares (82 espacios, con algo menos de 1,5 millones de ha de extensión), como ya se ha visto, las iniciativas posteriores han incrementado dicha superficie. Y a ellas se han ido sumando progresivamente las áreas preservadas a partir de los acuerdos de creación de redes de espacios de interés natural a escala comunitaria. Aun así, todavía existen zonas contempladas en estos Planes que no están recogidas en ninguno de los inventarios posteriores, con lo que la decisión del POTA de designarlas de forma específica como componentes del SPTA adquiere pleno sentido. 
La dificultad estriba en la falta de desarrollo de parte de la normativa de protección de dichos espacios establecida por los PEPMF. En este sentido, ya Zoido (ibídem) señalaba que una de las críticas más frecuentes que estos planes habían recibido era la relativa al incumplimiento de lo previsto, tanto por indisciplina como por disposiciones contrarias a sus determinaciones por parte del planeamiento urbanístico posterior. Hay que considerar que, aunque los citados Planes fueron aprobados en la década de los 80, la publicación de los mismos no se realizó hasta 2007. Mientras -como explícitamente se señala en las Resoluciones de publicación- tanto el planeamiento urbanístico general como la planificación territorial y ambiental (de la que los PEPMF resultan subsidiarios y supletorios) fueron sustituyendo algunas de las previsiones de éstos por las propias.

Con la publicación de los Planes (derivada de su inclusión en el POTA) podría entenderse que la situación se ha corregido. No obstante, no puede olvidarse que, por su propia naturaleza de Planes Especiales, éstos no son instrumentos vinculantes para el planeamiento municipal, lo que, sin duda alguna, debilita sensiblemente su efectividad. Si a ello unimos el hecho de que, como expresamente se indica en los correspondientes apartados de desarrollo de las determinaciones, muchas de ellas deberán ejecutarse a través de los Planes Generales o de los instrumentos de ordenación equivalentes y sabemos de la tardanza en su renovación (los PEPMF no establecen plazos de revisión), queda pendiente de actuaciones posteriores el cumplimiento de parte de lo dispuesto y, en buena medida, complica su tratamiento dentro del SPTA.

\subsubsection{Zonas que constituyen el dominio público hidráulico y marítimo terrestre}

Los bienes integrantes del dominio público hidráulico vienen fijados por el artículo 2 del Texto Refundido de la Ley de Aguas (Real Decreto Legislativo 1/2001, de 20 de Julio), en el cual se establecen como tales las aguas continentales superficiales y subterráneas, los cauces de corrientes naturales, los lechos de lagos y lagunas y de los embalses superficiales en cursos públicos, los acuíferos subterráneos y las aguas procedentes de desalación del agua del mar. Respecto a todos ellos el texto legal define los elementos y zonas que los componen y determina el régimen de usos, actividades y actuaciones. En cuanto al dominio marítimo terrestre su determinación la realiza la propia Constitución de 1978 y, a su amparo, la Ley de Costas (Ley 22/1988, de 28 de Julio) según la cual forman parte del mismo, entre otras, las playas, sistemas dunares, acantilados, terrenos ganados al mar por causas naturales o artificiales, las marismas y los humedales litorales.

No obstante, tanto en un caso como en otro, la delimitación de los terrenos con afección demanial puede dar lugar a conflictos con los colindantes, de ahí que los mencionados u otros textos jurídicos complementarios (en concreto, el Reglamento de Dominio Público Hidráulico y las revisiones al mismo, aprobadas por el $R D$ 606/2003 y RD 9/2008) establezcan el procedimiento administrativo de deslinde a través del cual se perfila de forma concreta la superficie física afectada.

El contenido y el sistema de demarcación están, pues, perfectamente regulados por Ley; lo que no se ha completado ha sido su aplicación efectiva. La delimitación del dominio marítimo terrestre en Andalucía está muy avanzada, ya que, según datos del Ministerio de Medio Ambiente y Medio Rural y Marino, a 31 de Marzo de 2011, en todas las provincias 
los deslindes estaban realizados en más del $90 \%$ de la costa, salvo en Huelva y Málaga donde el porcentaje era superior al $80 \%$. Pero no ocurre lo mismo en lo que atañe a los cursos fluviales, a pesar de que ya en 1993 este organismo puso en marcha el denominado Proyecto LINDE con el objetivo de concretar físicamente y deslindar en todas las cuencas sobre las que la Administración Central mantenía su competencia, al menos, aquellas zonas sometidas a mayor presión (recuérdese que el traspaso de dichas competencias en lo que afecta a las cuencas intracomunitarias a Andalucía se produce a través de los Reales Decretos 2130/2004 y 1560/2006 -Serrano, 2010-, con lo que pasa un largo periodo desde el inicio del proyecto hasta que tiene lugar el cambio de situación). A pesar del tiempo transcurrido y de que años después incluso se planteó una ampliación del proyecto con el objeto de conocer mejor el alcance de la zona demanial (Villarroya, 2004), el trabajo sigue estando lejos de ser concluido. Y eso hace que, en lo que afecta a la región, según datos de la Consejería de Medio Ambiente, sólo haya deslindados de forma efectiva $862 \mathrm{~km}$ (lo que supone poco más de $30.000 \mathrm{ha}$ ) de un total de $45.836 \mathrm{~km}$ que, por lo que recoge el Borrador del Plan Director de Riberas de Andalucía, es la longitud total de la red hidrográfica. Aunque la falta de declaración en modo alguno suponga la inexistencia del dominio público, de cara a su gestión dentro el SPTA es una situación, a todas luces, poco favorecedora.

\subsubsection{Vías pecuarias y otros «caminos naturales»}

A pesar del considerable avance que su deslinde ha experimentado en los últimos años, algo similar cabe decir en relación con las «vías pecuarias» que, junto con otros «caminos naturales», constituyen el siguiente grupo de componentes naturales del Sistema mencionado por el POTA.

En este sentido, la Ley 3/1995, de 23 de Marzo, de Vías Pecuarias reconoce, además de su uso tradicional como líneas de tránsito para la cabaña ganadera y de acceso a las fincas agrícolas colindantes, la función que pueden desempeñar como corredores ecológicos, espacios de uso recreativo, instrumentos para favorecer el contacto con la naturaleza y elementos de mejora y diversidad paisajística. Con este precedente, la Consejería de Medio Ambiente de la Junta de Andalucía, siguiendo el desarrollo del Reglamento de Vías Pecuarias de Andalucía aprobado por Decreto 155/98, de 21 de Julio, inició a finales de 1999 la elaboración de un Plan de Recuperación y Ordenación de este tipo de bienes públicos. Gracias a él, se definió la Red Andaluza de Vías Pecuarias, que se entiende como el conjunto de cañadas, cordeles y veredas para el que es factible la recuperación y que tiene potencial de acogida de usos alternativos. Y, además, se puso en marcha un programa de rescate, restauración y mantenimiento a través del cual recuperar para el dominio público y revalorizar unos caminos seculares que el abandono y la falta de vigilancia habían dejado al albur de usurpaciones particulares. Este trabajo identificó más de $33.000 \mathrm{~km}$ de vías de la trashumancia, de las cuales (excluyendo los tramos solapados con vías de comunicación modernas, los que han quedado incluidos en poblaciones, los que presentan falta de continuidad y los que se cruzan con embalses) terminó por seleccionar $24.015 \mathrm{~km}$ para formar parte de una red que conecta entre sí todos los municipios y comarcas de Andalucía y a ésta con el resto de la Península.

A partir de esa selección, el siguiente paso para la recuperación efectiva es la clasificación y el deslinde que, según la Ley 3/1995, es el procedimiento para declarar la posesión y la titu- 
laridad demanial de la vía a favor de la Comunidad Autónoma. Pues bien, según datos de la Consejería de Medio Ambiente, para el primer trimestre de 2011 se habían deslindado 8.183 $\mathrm{km}$, es decir, el 35\% de la red, pero esta cifra, aun siendo importante, dista mucho de la longitud total prevista y ni siquiera alcanza los $9.442 \mathrm{~km}$ catalogados en el Plan de Ordenación y Recuperación como de nivel prioritario. Lógicamente, más lejos aún está el desarrollo de las propuestas de actuación que su puesta en valor conlleva (amojonamiento, recuperación, limpieza, señalización, restauración de elementos asociados al tráfico ganadero -abrevaderos, majadas, descansaderos...-, implantación de equipamientos de uso público, etc.). Hasta que no se completen las actuaciones, parecen claros los inconvenientes que se derivan de esta situación tanto para el conocimiento preciso de espacios y elementos afectados como para su funcionamiento pleno y coherente dentro la red patrimonial de Andalucía, más todavía si se tiene en cuenta que el propio POTA otorga a estas rutas un importante papel relacional entre los ejes de comunicación que articulan física y funcionalmente el SPTA.

Más complicada, no obstante, es la situación de los llamados «caminos naturales» en la medida en que ni siquiera el propio contenido del término está definido en el Plan de Ordenación.

Tratando de arrojar luz sobre el asunto hemos consultado el Programa Español de Caminos Naturales, una iniciativa aún en vigor que puso en marcha el entonces Ministerio de Obras Públicas, Transportes y Medio Ambiente en 1993, en el cual, aunque inicialmente sólo se integraron trazados abandonados de uso ferroviario (las conocidas Vías Verdes), desde 1996 también se consideraron como infraestructuras susceptibles de actuación tanto las líneas de ferrocarril comercial abandonadas y los ferrocarriles mineros en desuso como las vías pecuarias, los caminos de servicio de canales con expropiación suficiente como para permitir un uso alternativo ecoturístico, los que discurren por las servidumbres del Dominio Público Hidráulico en las márgenes de los ríos, las calzadas romanas y otras rutas históricas, etc. (Martín, 2004). Como es evidente, se trata de un variado conjunto de itinerarios sobre cuyo interés patrimonial no cabe duda; el problema es que carece de delimitación real. Así lo constata un reciente estudio realizado por el Observatorio de Caminos Naturales e Itinerarios No Motorizados (2011: 5) en el que se dice expresamente que «no es posible conocer con mayor exactitud cuál es la extensión de esas redes y cuál es la red de itinerarios no motorizados ni siquiera a escala autonómica». Si a ello se añaden las dudas que muestra el Observatorio sobre la precisión en el contenido de los repertorios de algunas de estas vías realizados hasta el momento o la reiterada repetición de las figuras que hace que una misma ruta esté incluida a la vez en varias redes diferentes, el panorama es ciertamente confuso.

Y tampoco se aclara si se busca información en la página web de la Consejería de Medio Ambiente de la Junta donde el único epígrafe específico sobre el tema recoge exclusivamente menciones a Vías Pecuarias y Corredores y Puertas Verdes, sin aludir en ningún momento a los «otros caminos naturales» a los que se refiere SPTA. Lo que no es óbice para que cualquiera de ellos pueda considerarse como tal. Así, Corredores y Puertas Verdes son proyectos con funcionalidad ecológica y socioeconómica que tratan de fomentar el acercamiento de la ciudadanía al espacio rural, a los entornos naturales o a puntos de interés cultural (en concreto el de Puertas Verdes orientado de forma específica a municipios con más de 50.000 habitantes). En ambos casos, incluyen actuaciones de recuperación paisajística, de adecuación del viario y, en ocasiones, de construcción de carriles bici o de adaptación de caminos 
para su uso ecuestre, etc. siempre apoyadas en la red de vías pecuarias. Parece, pues, que en efecto se trata de lo que pueden entenderse como «caminos naturales», aunque nada se diga al respecto; como tampoco se hace en relación con ninguna otra tipología viaria que pudiera ser asimilable y sobre la que, en consecuencia, no se ofrece información aprovechable en la definición del SPTA.

Si a todo ello se une el hecho de que, al margen de la normativa sobre vías pecuarias, no existe ningún instrumento legislativo sobre caminos naturales en España que sustente las actuaciones estatales o autonómicas en la materia, queda claro que nos movemos en un marco tan impreciso como inseguro de cara a su regulación, protección y uso.

\subsubsection{Inventarios de georrecursos y de humedales}

Respecto a los georrecursos puede decirse que en los años 90 se habían puesto en marcha diversas iniciativas que dieron como resultado la inclusión de varios espacios con valor geológico en el Inventario de Espacios Protegidos de Andalucía y, tiempo después, la incorporación a la RENPA de ciertos Monumentos Naturales específicamente geológicos. Pero será a partir de 2000 cuando tengan lugar las principales actuaciones orientadas al inventariado, evaluación, protección y gestión integrada del patrimonio geológico (entendido éste como el conjunto de formaciones y estructuras geológicas, paisajes geomorfológicos, yacimientos paleontológicos y mineralógicos, etc. de significativo valor para reconocer, estudiar e interpretar la evolución geológica del territorio) y a su utilización como recurso para el desarrollo sostenible. Con este fin, en 2001 se inició la elaboración de una Estrategia de Conservación Integrada de la Geodiversidad y, derivada de ella, la creación de un Inventario Andaluz de Georrecursos en el que se recogiesen sistemáticamente los lugares o espacios de la región con alto valor geológico, tanto desde el punto de vista científico como didáctico, y con potencialidad para su aprovechamiento económico o turístico.

Actualmente el Inventario identifica, cataloga y valora 662 localidades de interés, de las cuales el $57 \%$ cuenta con algún grado de protección ambiental por estar incluidas en la RENPA o en la Red Natura 2000. Pero, además, gracias a la aprobación de la Ley 42/2007 del Patrimonio Natural y la Biodiversidad, que por primera vez integra de forma expresa la geodiversidad y el patrimonio geológico en el patrimonio natural, se dispone de un marco normativo sobre el que apoyar jurídicamente las actuaciones sobre los georrecursos. La última iniciativa en esta línea ha sido la aprobación en octubre de 2010 de la Estrategia Andaluza de Gestión Integrada de la Geodiversidad, un documento de referencia pionero en España encaminado a la adopción de medidas de preservación y a la promoción del patrimonio geológico como activo socioeconómico cuyo corto recorrido impide, por el momento, una valoración de posibles resultados.

En cuanto al Inventario de Humedales de Andalucía se puede decir que es fruto de los avances realizados gracias al Plan Andaluz de Humedales, un documento marco para la planificación, ordenación y gestión de este tipo de espacios aprobado en 2002. El Plan, recogiendo el imperativo de la Ley 4/1989 de Conservación de los Espacios Naturales, la Fauna y la Flora de elaborar un inventario de esta naturaleza a escala nacional a partir de la información proporcionada por las Comunidades Autónomas, plantea por primera vez en esta región la necesidad de conocer el número, localización y estado de las áreas encharcables y llevar a 
cabo una recopilación sistemática de datos sobre las mismas como paso indispensable para poner en marcha un Programa de Acción coordinado que posibilite su protección y el uso sostenible de sus servicios ambientales. Así, a través del Decreto 98/2004 por el que se crea el Inventario de Humedales de Andalucía y el Comité Andaluz de Humedales empezó a tomar forma como un catálogo de espacios palustres con especial valor natural (ya sea edafológico, geológico, geomorfológico, hídrico, ecológico o cultural) a los cuales, como obliga la ley, se ha de prestar especial atención con independencia de que estén o no declarados como ENP. De hecho, ocurre que gran parte de los espacios inventariados cuentan con protección específica a través de distintas figuras. No obstante, aún queda un número significativo de ellos no amparados por ninguna catalogación los cuales, gracias a esta iniciativa, también se benefician de protección legal y amplían sus posibilidades de acogerse a medidas de restauración. Por su parte, los datos de todos los humedales quedan integrados en la REDIAM, lo que facilita su conocimiento por las instancias competentes y, en el caso que nos atañe, por el SPTA.

\subsection{Los componentes de carácter cultural}

$\mathrm{Si}$, como hemos visto, la relación de componentes naturales del SPTA que el POTA establece presenta algunas dificultades, la cuestión se hace más problemática cuando se atiende a los bienes de carácter cultural debido a la insuficiente definición de algunos de ellos y a la distinta situación en que se encuentran con respecto a la legislación de protección del patrimonio.

\subsubsection{Ciudades históricas protegidas como Conjuntos Históricos}

No es el caso del primero de los grupos reseñados en el Plan, el referido a las ciudades históricas protegidas como «Conjuntos Históricos». Definidos éstos por la Ley 14/2007, de 26 de noviembre, del Patrimonio Histórico de Andalucía como «agrupaciones de construcciones urbanas o rurales junto con los accidentes geográficos que las conforman, relevantes por su interés histórico, arqueológico, paleontológico, artístico, etnológico, industrial, científico, social o técnico, con coherencia suficiente para constituir unidades susceptibles de clara delimitación», constituyen una categoría antigua, que ya se contemplaba en el Real Decreto-Ley de 9 de Agosto de 1926 sobre Protección, Conservación y Acrecentamiento de la Riqueza Artística, se retomaría en la Ley de 1933 y permanecería en la 16/1985 del Patrimonio Histórico Español aún en vigor (GDRU, 2008).

En el momento actual, existen en Andalucía un total de 132 Conjuntos Históricos, 127 de ellos de carácter urbano, todos incluidos en el Catálogo General de Patrimonio Histórico Andaluz con la categoría de Bien de Interés Cultural (BIC) y, por lo tanto, directamente protegidos tanto por la legislación sobre patrimonio como por la de carácter territorial y urbanístico. En este sentido, ya la Ley de Patrimonio Histórico Español de 1985, en sintonía con la legislación urbanística vigente en el momento, obligaba a los ayuntamientos a redactar y tramitar la aprobación de Planes Especiales de Protección (PEP) cuando se produjera la declaración de un conjunto histórico como BIC. De esta manera, se establecía un procedimiento de intervención sobre los mismos que, más allá del amparo prestado por los organismos competentes en materia cultural, obligaba a los entes locales a cooperar en su conservación 
y custodia a través de su actividad urbanística -función, por otra parte, ya contemplada en el Texto Refundido de la Ley sobre Régimen del Suelo y Ordenación Urbana de 1976 pero que ahora adquiere un carácter imperativo- (Anguita, 2009). Sin embargo, la ley autonómica andaluza va más allá. En aras de conseguir una mayor ligazón entre la legislación urbanística y la patrimonial y reconociendo la dificultad de lograr una adecuada conservación de los bienes culturales con el único concurso de medidas de protección y fomento que esta última propicia, obliga a los municipios a regular las intervenciones en sus conjuntos históricos mediante el planeamiento general o los PEP. Además, reglamenta los contenidos de protección que deben incluir dichos planes, establece la obligatoriedad de revisarlos y adaptarlos a las necesidades existentes cuando se produzca, no ya la declaración, sino la sola inscripción de bienes inmuebles en el Catálogo General del Patrimonio Histórico Andaluz y fija un plazo máximo de dos años desde la publicación del registro (sólo prorrogable bajo condiciones y previa petición razonada) para realizar la actualización (Capítulo II). Con esta estricta ordenación, parece que la gestión de estas ciudades históricas dentro del SPTA puede llevarse a cabo en un marco rigurosamente delimitado.

\subsubsection{Otras ciudades históricas no protegidas pero equivalentes en valores a los Conjuntos Históricos}

Más complicada resulta la identificación y el consiguiente tratamiento de los núcleos que el POTA tipifica como «otras ciudades históricas no protegidas pero equivalentes en valores a los Conjuntos Históricos», respecto a las que los redactores del Plan no ofrecen información suficiente para poder conocer de forma inequívoca a cuáles se está haciendo referencia.

En relación con este tema, Feria et alii (2002) explican que la calificación de los núcleos declarados Conjuntos Históricos en la región no ha sido fruto de un proceso unitario sino consecuencia de iniciativas individuales por parte de los organismos provinciales competentes, resultando así una situación en la que se observan carencias difícilmente explicables y lagunas territoriales muy significativas. A su juicio, a ello coadyuva el hecho de que no existan unas normas que señalen sin margen para la duda cuáles deben ser considerados Centros Históricos y cuáles no, a pesar de que usualmente se ponderen ciertas características tenidas por relevantes (los valores correspondientes a su contribución a un orden territorial general, los paisajísticos y los derivados de su emplazamiento; los valores intrínsecos a su trama urbana; y los correspondientes a los tipos arquitectónicos, elementos constructivos y riqueza monumental). A partir de esos parámetros, su estudio sobre Redes de Centros Históricos en Andalucía analiza un repertorio muy amplio de núcleos considerados de interés, sólo algunos de los cuales cuentan con declaración legal.

También sobre la base de unos criterios similares, ya con anterioridad un trabajo de encargo de la Dirección General de Ordenación del Territorio y Urbanismo centrado en el Análisis Urbanístico de Centros Históricos de Andalucía había seleccionado un total de 122 núcleos con cascos históricos relevantes, de los cuales la mayor parte contaba con declaración legal de BIC o tenía incoados o iniciados expedientes para tal declaración. Sin embargo, en catorce de ellos no se había puesto en marcha trámite alguno en esta dirección y únicamente contaban con un Documento de Informe-Diagnóstico de su Centro Histórico redactado por la Consejería de Obras Públicas y Transportes, a pesar de poseer «valores suficientes para que se hubiera justificado el inicio de expedientes de incoación/declaración». Junto a éstos, el 
estudio reconocía la existencia de áreas, algunas de gran amplitud, «a las que los procesos de incoación/declaración nunca llegaron, pero donde se pueden encontrar núcleos urbanos que presentan similares, o incluso mayores, valores que algunos de los 108 elegidos», destacando los vacíos de la mitad Norte de la provincia de Córdoba (Valle del Guadiato, Los Pedroches, Sierra de Hornachuelos), gran parte de la provincia de Granada, así como casi toda la de Almería (Alpujarra, Valles del Andrax y Almanzora, Levante, Poniente, etc.) (Consejería de Obras Públicas y Transportes, 2001: 11, 98).

Posiblemente, es en el conocimiento de esta situación en lo que el POTA se basa a la hora de incluir entre los componentes del SPTA a esas ciudades sin protección pero con valores equiparables a los de los conjuntos incluidos en el Catálogo del Patrimonio Histórico; pero ello no resuelve el problema. En primer lugar, porque publicaciones como las anteriores no coinciden en sus contenidos (tampoco es su propósito identificar de manera exhaustiva cuáles pueden ser dichos núcleos); en segundo, porque siguen sin establecerse por parte de la administración unos criterios objetivos y homogéneos de valoración que faciliten una selección sistemática; y, en tercer lugar, porque, desde un punto de vista legal, la mera intuición e incluso el consenso generalizado sobre el interés de un bien no constituye base suficiente en la que apoyar iniciativas de gestión patrimonial; menos aún, en un ámbito tan sensible como el del urbanismo en el que, de no haber una normativa precisa, el conflicto de intereses suele provocar serios enfrentamientos. Y es que no debe olvidarse que bien cultural no es «aquel que presenta un interés de esta naturaleza, sino el que presentándolo ha sido expresamente declarado como tal en aplicación de la normativa en cada momento vigente»(Barrero, 1998: s.p.); lo cual hace difícil la salvaguarda de conjuntos sin algún reconocimiento.

\subsubsection{Patrimonio inmueble con categoría BIC o inscrito en el Catálogo General del Patrimonio Histó- rico de Andalucía}

Siguiendo con la relación de componentes culturales del Sistema, el POTA menciona a continuación el «Patrimonio Inmueble con categoría de BIC o inscrito en el Catálogo General del Patrimonio Histórico de Andalucía».

Los BIC, según recoge el art. 9 de la Ley de Patrimonio Histórico Español, son todos aquellos bienes que «deben gozar de singular protección y tutela» en razón de su máxima relevancia cultural, considerándose como tales los que así se declaren, además de los «que con anterioridad hayan sido declarados histórico-artísticos o incluidos en el Inventario del Patrimonio Artístico y Arqueológico de España» (Disposición Adicional Primera). De éstos, los de carácter inmueble, a los que se refiere el Plan, se clasifican en distintas categorías, algunas de ellas tradicionalmente consagradas -Conjunto Histórico, Monumento, Zona Arqueológica, Jardín Histórico y Sitio Histórico-; otra, la de Lugar de Interés Etnológico, creada por la Ley 1/1991, de 3 de Julio, de Patrimonio Histórico de Andalucía; y dos nuevas, los Lugares de Interés Industrial y las Zonas Patrimoniales, incorporadas por la Ley 14/2007. En Andalucía los BIC están inscritos en el Catálogo General del Patrimonio Histórico; pero, además, entendiendo que no todos los elementos y espacios patrimoniales poseen la misma relevancia o el mismo interés individual, en él también se incluyen los llamados «bienes de catalogación general» que corresponden a los que, aun siendo muy destacables, no alcanzan 
el grado de excelencia de los primeros, sin que ello sea óbice, no obstante, para que sigan mereciendo singular protección y tutela (Becerra, 2009).

Dada la consideración marcadamente monumentalista del patrimonio que ha impregnado durante decenios la declaración de bienes culturales así como la incorporación de nuevas figuras en fechas recientes, la actual composición del Catálogo es bastante desigual (vid. cuadro 2). En cuanto a la distribución territorial las diferencias están ligadas, por una parte, a la propia historia, que ha dejado testimonios especialmente numerosos y continuos en áreas como el Valle del Guadalquivir, las laderas de las Sierras Subbéticas, los pasillos intrabéticos y toda la franja costera, a excepción de los espacios marismeños onubeneses que, como ocurre con los ámbitos de montaña menos poblados, cuentan con un número menor de bienes reconocidos. Pero, por otra, el desequilibrio en el número de declaraciones también tiene que ver con los intereses que tradicionalmente han primado en la consideración de los bienes y que ha llevado a despreciar muchas manifestaciones culturales notables pero carentes de monumentalidad. Es precisamente en relación con todos ellos donde una gestión adecuada parece verdaderamente difícil.

Cuadro 2

CATÁLOGO GENERAL DE PATRIMONIO HISTÓRICO. Inscripciones por tipología jurídica

\begin{tabular}{|c|c|c|c|c|c|c|c|c|c|}
\hline & ALMERÍA & CÁDIZ & CÓRDOBA & GRANADA & HUELVA & JAÉN & MÁLAGA & SEVILLA & TOTAL \\
\hline $\begin{array}{l}\text { Jardín } \\
\text { Histórico }\end{array}$ & 0 & 0 & 2 & 48 & 0 & 0 & 3 & 3 & 56 \\
\hline $\begin{array}{l}\text { Paraje } \\
\text { Pintoresco }\end{array}$ & 0 & 0 & 2 & 0 & 0 & 1 & 3 & 0 & 6 \\
\hline $\begin{array}{l}\text { Lugar de } \\
\text { Interés } \\
\text { Industrial }\end{array}$ & 0 & 0 & 0 & 4 & 4 & 1 & 0 & 0 & 9 \\
\hline $\begin{array}{l}\text { Zona } \\
\text { Arqueológica }\end{array}$ & 55 & 41 & 17 & 37 & 27 & 13 & 64 & 22 & 276 \\
\hline $\begin{array}{l}\text { Zona } \\
\text { Patrimonial }\end{array}$ & 0 & 0 & 0 & 0 & 3 & 12 & 0 & 0 & 15 \\
\hline $\begin{array}{l}\text { Sitio } \\
\text { Histórico }\end{array}$ & 1 & 5 & 23 & 69 & 2 & 3 & 2 & 1 & 106 \\
\hline $\begin{array}{l}\text { Conjunto } \\
\text { Histórico }\end{array}$ & 3 & 27 & 11 & 15 & 25 & 23 & 9 & 19 & 132 \\
\hline $\begin{array}{l}\text { Lugar de } \\
\text { Interés } \\
\text { Etnológico }\end{array}$ & 0 & 3 & 1 & 2 & 28 & 2 & 0 & 41 & 77 \\
\hline Monumento & 202 & 303 & 277 & 456 & 130 & 328 & 235 & 275 & 2206 \\
\hline Otros & 2 & 3 & 4 & 3 & 2 & 2 & 2 & 6 & 24 \\
\hline $\begin{array}{l}\text { Sin tipología } \\
\text { jurídica } \\
\text { especificada }\end{array}$ & 267 & 60 & 200 & 13 & 107 & 147 & 45 & 105 & 944 \\
\hline TOTAL & 530 & 442 & 537 & 647 & 328 & 532 & 363 & 472 & 3851 \\
\hline
\end{tabular}

Fuente: Consejería de Cultura. Elaboración propia. 


\subsubsection{Otros yacimientos arqueológicos y elementos del patrimonio cultural}

El cambio en la percepción del patrimonio que reflejan las últimas modificaciones en la ley autonómica se evidencia, no obstante, con mayor claridad en la composición del Inventario de Bienes Reconocidos del Patrimonio Histórico Andaluz con el que en estos momentos cabe poner en relación el último de los epígrafes de identificación de los componentes del SPTA, que es el correspondiente a «otros yacimientos arqueológicos y elementos del patrimonio cultural (hábitat de cuevas, arquitectura popular, etc.»). En este sentido, hay que empezar reconociendo, una vez más, la vaguedad y pobreza en las indicaciones del POTA que, con una referencia tan poco precisa como la de «elementos del patrimonio cultural» (que, por otra parte, parece contraponer a los yacimientos arqueológicos, como si éstos no se incluyeran en aquéllos) deja abierta la posibilidad de elección discrecional sobre unos contenidos que la única alusión al hábitat de cuevas y arquitectura popular está muy lejos de agotar. Y esto, en un momento como el de la aprobación del POTA en el que la protección efectiva de los bienes patrimoniales se producía únicamente a través de su catalogación para la que, como es sabido, se precisa de una perfecta identificación, una delimitación concreta y una descripción y justificación detallada de sus valores.

Por suerte, la Ley de Patrimonio Histórico de Andalucía de 2007 ha venido a resolver el problema a través de la creación del Inventario de Bienes Reconocidos, cuyo objeto es recoger «aquellos bienes que, fruto de un estudio o investigación científica, se identifican como integrantes de nuestro Patrimonio Histórico» (Título Preliminar). Instrumento complementario al Catálogo, el Inventario incluye todos los inmuebles y los espacios vinculados a actividades de interés etnológico que el organismo competente reconozca como integrantes del acervo patrimonial de la región así como los que vengan señalados por los catálogos urbanísticos (en los que, por otra parte, también deberán incluirse cuando se produzca su revisión, las nuevas inscripciones del Inventario). Y es especialmente reseñable el hecho de que su mera incorporación al mismo conlleva el deber de conservación, mantenimiento y custodia lo que, sin duda, incrementa su seguridad jurídica. En relación con el SPTA parece lógico convenir que deben ser éstos los bienes a considerar puesto que son los que efectivamente están identificados y los que cuentan con protección preventiva.

Hoy la Base de Datos del Patrimonio Inmueble de Andalucía incluye más de 20.000 registros, de los cuales unos 12.000 corresponden a entidades arqueológicas, alrededor de 4.300 son arquitectónicos y más de 3.800 son tipologías relacionadas con el patrimonio etnológico. Aunque a estas cifras hay que restarle los bienes ya incluidos en el Catálogo General de Patrimonio Histórico, el volumen de elementos identificados es muy importante; y es que la Dirección General de Bienes Culturales está realizando un esfuerzo considerable para conocer los más diversos componentes del patrimonio andaluz. Con este objetivo, está desarrollando inventarios temáticos de muy diversa índole (entre ellos, los de ermitas, plazas de toros, fuentes, yacimientos arqueológicos, arte rupestre, arquitectura popular, arquitectura moderna, patrimonio industrial, etc.) cuyo contenido, que por ley se incorpora al Inventario de Bienes Reconocidos sin más requisito que el de proporcionar su identificación, descripción y localización, se incrementa de forma significativa todos los años (Becerra, 2009). Como cabe suponer, gracias a la información que aquí se incluye, el Inventario se convierte en una herramienta de primer orden para la gestión patrimonial que el POTA preconiza. 


\section{CONCLUSIONES}

La definición dentro del modelo territorial establecido por el POTA del SPTA y la formulación de proposiciones encaminadas al tratamiento conjunto de los espacios y elementos que lo componen han supuesto un verdadero hito en el ámbito del planeamiento ya que se aborda por primera vez la gestión unitaria del patrimonio natural y cultural de la región desde su entendimiento como una red integrada e internamente articulada, con la intención de superar la visión fragmentaria y descontextualizada que venía siendo tradicional y de impulsar su revalorización como recurso para el desarrollo socioeconómico de Andalucía. No obstante, ya en la propia propuesta y diseño del SPTA y en la determinación de sus instrumentos de gestión se aprecian deficiencias que condicionan seriamente su operatividad. Así, aunque muchos de sus componentes son nítidamente identificables, uno de los puntos débiles del Sistema es la insuficiente definición de algunos otros, en unos casos, por la vaguedad y falta de precisión a la hora de fijar los enunciados que identifican los elementos y espacios que deben conformarlo; otras veces, por la situación legal en la que éstos se encuentran como consecuencia del distinto grado de aplicación de la normativa vigente; y en otras ocasiones, por la evolución que ha ido experimentando la reglamentación con posterioridad a la aprobación del POTA y que, al menos de forma expresa, no siempre está contemplada. El hecho de que el propio Plan tenga rango de norma jurídica (y, por lo tanto, sea capaz de establecer sus propias directrices de protección) no corrige la anomalía que supone dar el mismo valor estructurante desde el punto de vista territorial a cualquier tipo de elemento previamente declarado, con independencia de su rango o carácter, ni tampoco suple las deficiencias derivadas de integrar en una misma unidad de gestión a conjuntos desiguales y, con frecuencia, imprecisos.

Si a ello se une que, a pesar del tiempo transcurrido desde la aprobación de las directrices generales, no se ha puesto en funcionamiento el Sistema de Información de espacios y bienes catalogados, previsto como instrumento básico para el conocimiento y la gestión del SPTA, y que tampoco se han elaborado catálogos integrados de bienes patrimoniales (ni a la escala de las unidades territoriales que allí se establecen ni a la de los instrumentos de ordenación de escala subregional), premisas éstas indispensables para la puesta en marcha de cualquier tipo de actuación integrada, las dudas sobre la efectividad real que el Sistema pueda llegar a tener surgen de forma inevitable. En estas circunstancias, pues, a futuro será preciso estar atentos a los resultados que en la práctica están teniendo unas estrategias de desarrollo territorial articuladas sobre tan inestable base.

\section{BIBLIOGRAFÍA}

ABAD GONZÁLEZ, L. (coord.) (2006): El patrimonio cultural como factor de desarrollo: estudios multidisciplinares. Universidad de Castilla-La Mancha, Cuenca.

AGUDO TORRICO, J. (2009): «Patrimonio histórico y desarrollo territorial». En Patrimonio histórico y desarrollo territorial (CASTILLO, J., CEJUDO, E. y ORTEGA, A., eds.). Sevilla, Universidad Internacional de Andalucía, 96-137.

ANGUITA CANTERO, R. (2009): «La responsabilidad local en la protección del Patrimonio Histórico español: Planeamiento y Catálogos Urbanísticos». En Patrimonio histórico y 
desarrollo territorial (CASTILLO, J., CEJUDO, E. y ORTEGA, A., eds.). Sevilla, Universidad Internacional de Andalucía, 214-241.

ARAQUE JIMÉNEZ, E. et alii. (2005): Las montañas españolas: territorio, sociedades, patrimonio y cultura: materiales para el conocimiento, la promoción y difusión de los espacios de montaña. Madrid, Ministerio de Ciencia y Tecnología, CD-Rom.

BARRERO RODRÍGUEZ, M.C. (1998): «Los Conjuntos Históricos y el planeamiento de protección. Especial referencia a la Comunidad Autónoma de Andalucía». Medio Ambiente y Derecho: Revista Electrónica de protección ambiental, $\mathrm{n}^{\mathrm{o}}$ 0. Disponible en: http://huespedes.cica.es/aliens/gimadus/00/CONJUNTOS_HIST\%d3RICOS.htm

BECERRA GARCÍA, J.M. (2009): «La protección del Patrimonio Histórico en Andalucía». En: Protección Jurídica del Patrimonio Cultural (RODRÍGUEZ LEÓN, L.C., coord.). Sevilla, Instituto Andaluz de Administración Pública, 163-179.

BELLIDO, M.A. (2009): «La musealización del territorio: posibilidades para la protección y aprovechamiento productivo del Patrimonio». En Patrimonio histórico y desarrollo territorial (CASTILLO, J., CEJUDO, E. y ORTEGA, A., eds.). Sevilla, Universidad Internacional de Andalucía, 266-286.

BENAVENT, M. (2006): La ordenación del territorio en España. Sevilla, Universidad de Sevilla. Consejería de Obras Públicas y Transportes.

BOSQUE MAUREL, J. (1995): «Patrimonio turístico e identidad cultural: el Patrimonio de la Humanidad». Revista de Geografía, n. ${ }^{\circ}$ 5,173-180.

CAÑIZARES RUIZ, C. (2009): «Cultura y patrimonio en clave territorial: las aportaciones del geógrafo». En Territorios, sociedades y políticas (FERIA, J.M., GARCÍA, A. y OJEDA, J.F., eds.). Sevilla, Universidad Pablo de Olavide, AGE, 93-106.

CARAVACA BARROSO, I. et al. (1997): «Patrimonio cultural, territorio y políticas públicas. El caso de Andalucía». Estudios Regionales, n 47, 143-160.

CASTILlO RUIZ, J. (2009): «La dimensión territorial del Patrimonio Histórico». En Patrimonio histórico y desarrollo territorial (CASTILLO, J., CEJUDO, E. y ORTEGA, A., eds.). Sevilla, Universidad Internacional de Andalucía, 27-48.

CONSEJO DE EUROPA (2000): Convenio Europeo del Paisaje. Florencia. Disponible en: http://www.femp.es/files/566-346-archivo/convenio\%20paisaje\%20FLORENCIA.pdf

CORTÉS PUYA, C. (2004): Recuperación del patrimonio cultural urbano como recurso turístico. Tesis doctoral de la Universidad Complutense de Madrid. Facultad de Geografía e Historia. Departamento de Geografía. Disponible en http://eprints.ucm.es/tesis/ghi/ucm-t25959.pdf

DIEGO LIAÑO, C. y GARCÍA CODRON, J.C. (2007): Los espacios naturales protegidos. Barcelona, Davinci.

FERIA TORIBIO, J.M. (1993): Los sistemas territoriales de asentamientos en Andalucía. Su organización a escala intermedia. Sevilla, Editorial de la Universidad de Sevilla.

- (2005): «El valor de la Naturaleza y la Cultura en los procesos de Desarrollo Territorial». En Jornadas de Patrimonio y Territorio (FERNÁNDEZ, V. y CARAVACA, I., coords). Sevilla, Consejería de Cultura de la Junta de Andalucía, 63-70.

- (2010): «Patrimonio territorial y desarrollo sostenible: un estudio comparativo en Iberoamérica y España». Estudios Geográficos, Vol. LXXI, nº 268, 129-159.

FERIA, J.M. et alii (2002): Redes de Centros Históricos en Andalucía. Sevilla, Dirección General de Bienes Culturales. 
FERNÁNDEZ CACHO, S. (2008): Patrimonio arqueológico y planificación territorial: estrategias de gestión para Andalucía. Sevilla, Consejería de Cultura. Universidad de Sevilla.

FERNÁNDEZ SALINAS, V. (2003): «El patrimonio andaluz en el cambio de milenio: retos y amenazas». I Jornadas sobre la protección y conservación del patrimonio histórico. Ed. Asociación de Amigos de Écija, 57-69.

FERNÁNDEZ SALINAS, V., CARAVACA BARROSO, I. et alii (coords.) (2004): Jornadas del Patrimonio y Territorio. Actas. Sevilla, Junta de Andalucía, Consejería de Cultura.

FERNANDEZ TABALES, A. y SANTOS PAVON, E. (1999): «Turismo y patrimonio histórico en Andalucía: magnitudes generales y estrategias de planificación», Boletín de la Asociación de Geógrafos Españoles, no 28, 119-134.

FLORIDO TRUJILlO, G. (2004): Patrimonio Rural, Paisaje y Territorio en la comarca de Debabarrena. San Sebastián, Debegesa, Agencia de Desarrollo Comarcal del Bajo Deba.

- (2007): «Paisaje y patrimonio como recursos básicos en espacios rurales marginales». En Habiter et vivre dans les campagnes de faible densité. Actes du 2 e colloque francoespagnol de géographie rurale. Presses Universitaires Blaise Palcal, Clermont-Ferrand, 465-480.

FLORIDO TRUJILLO, G. y LOZANO VALENCIA, P. (2005): «Las figuras de protección de los espacios naturales en las comunidades autónomas españolas: una puesta al día». Boletín de la $A G E, \mathrm{n}^{\circ} 40,57-81$.

GÓMEZ ZOTANO, J. y RIESCO CHUECA, P. (2010): Marco conceptual y metodológico para los paisajes españoles. Aplicación a tres escalas espaciales. Sevilla, Consejería de Obras Públicas y Vivienda. Centro de Estudios Paisaje y Territorio.

HERAN, F. (1979): «L`invention de l`Andalousie au XIX ${ }^{\mathrm{e}}$ s. dans la litterature de voyage: origine et fonction sociales de quelques images touristiques». En MIGUEL BERNAL, A. et al.: Tourisme et developpement regional en Andalousie. Paris, Éditions E. de Boccard, 21-40.

HERNÁNDEZ HERNÁNDEZ, F. (2002): El Patrimonio Cultural: la memoria recuperada. Gijón, Ediciones Trea.

JUNTA DE ANDALUCÍA (2001): Análisis Urbanístico de Centros Históricos de Andalucía: ciudades medias y pequeñas. Sevilla, Consejería de Obras Públicas y Transportes. Consejería de Cultura.

- (2006): Plan de Ordenación Territorial de Andalucía. Sevilla, Consejería de Obras Públicas y Transportes. Disponible en: http://www.juntadeandalucia.es obraspublicasyvivienda/obraspublicasyvivienda/portal-web/web/areas/ordenacion

- (2007): La RENPA en cifras (edición 2006). Sevilla, Consejería de Medio Ambiente.

LADRÓN DE GUEVARA SÁNCHEZ, C. (2007): «Origen, evolución y situación actual». En El Sistema de Información del Patrimonio Histórico de Andalucía (SIPHA) (LADRÓN DE GUEVARA, C. y MUÑOZ, V., coord.). Cuadernos PH, n 20, 14-29.

LÓPEZ GÓMEZ, J.F. y CIFUENTES VÉLEZ, E. (2009): «Lugares de nuestro pasado común: la definición del interés patrimonial del territorio». En Patrimonio histórico y desarrollo territorial (CASTILLO, J., CEJUDO, E. y ORTEGA, A., eds.). Sevilla, Universidad Internacional de Andalucía, 139-164. 
LÓPEZ ONTIVEROS, A. (2001): «Caracterización geográfica de Andalucía según la literatura viajera de los siglos XVIII y XIX». Ería, nº 54-55, 7-51.

- (2003): «De la imagen mítica de Andalucía a la realidad geográfica». En LÓPEZ ONTIVEROS, A. (Coord.): Geografía de Andalucía. Barcelona, Editorial Ariel, 13-34.

- (2007): «Descubrimiento y exaltación de los paisajes andaluces por los viajeros románticos». En VV.AA.: Los paisajes andaluces. Hitos y miradas en los siglos XIX y XX. Sevilla, Consejería de Obras Públicas y Transportes (Junta de Andalucía), 173-197.

MARTÍN GARCÍA, C.F. (2004): «Programa de Caminos Naturales del Ministerio de Medio Ambiente». Ingeniería y Territorio, $\mathrm{n}^{\circ}$ 69, 14-21.

MATA OLMO, R. (2008): «El paisaje, patrimonio y recurso para el desarrollo territorial sostenible: conocimiento y acción pública». Arbor: Ciencia, pensamiento y cultura, $\mathrm{n}^{\mathrm{o}}$ 729, 155-172.

- (2010): «La dimensión patrimonial del paisaje. Una mirada desde los espacios rurales». En Paisaje y patrimonio (MADEREUELO, J., dir.). Madrid, CDAN, Abada Editores, 31-73.

MOLINERO, F. (2007) (ed.): Espacios naturales protegidos. III Coloquio Hispano-Francés de Geografía Rural /IIIe Colloque Franco-Espagnol de Géographie Rurales. Ed. AGE, UNIA sede Antonio Machado, CNFG. CD-Rom.

MUÑOZ CRUZ, V. (2006): «El Sistema de Información del Patrimonio Histórico de Andalucía (SIPHA)». Berceo, nº 151, 117-132.

MULERO MENDIGORRI, A. (2001): «Los espacios naturales protegidos en Andalucía. Evolución, caracterización geográfica y singularidades». Ería, nº 54-55, 141-158.

- (2002): La protección de espacios naturales en España. Madrid, Mundi-Prensa.

- (2005): «Desarrollo rural y espacios naturales protegidos: los Planes de Desarrollo Sostenible». Ería, 68, 315-330.

MULERO, A., GARZÓN, R. y NARANJO, J. (2011): «El Sistema de Patrimonio Territorial y su significado en el contexto de las nuevas directrices de Ordenación del Territorio en Andalucía (España)». Conferencia Regional de la Unión Geográfica Internacional (UGI), (Santiago de Chile, 14 a 18 de Noviembre).Comunicaciones. En prensa.

OBSERVATORIO DE CAMINOS NATURALES E ITINERARIOS NO MOTORIZADOS (2011): Estudio de la situación de los caminos naturales e itinerarios no motorizados en España. Ministerio de Medio Ambiente y Medio Rural y Marino. Disponible en: http://www.marm.es/es/desarrollo-rural/temas/caminos-naturales/27072011_ Situaci\%C3\%B3n_Caminos_Naturales_e_Itinerarios_no_Motorizados_en_ Espa\%C3\%B1a_tcm7-170627.pdf

OCAÑA OCAÑA, M.C. (1999): «La Ordenación del Territorio en Andalucía». Cuadernos Económicos de Granada, $\mathrm{n}^{\circ}$ 10. Monográfico La Planificación del Territorio.

ORTEGA VALCÁRCEL, J. (1998): «El Patrimonio Territorial: el territorio como recurso cultural y económico». Ciudades: Revista del Instituto de Urbanística de la Universidad de Valladolid, $\mathrm{n}^{\circ}$ 4, 33-48.

(2004): «Áreas de montaña: de la supervivencia a la integración». Boletín de la AGE, $\mathrm{n}^{\circ} 38$, 5-28.

PULIDO FERNANDEZ, J .I. (2005): Criterios para una política turística sostenible en los parques naturales de Andalucía, Sevilla, Junta de Andalucía, Consejería de Turismo 
RODRÍGUEZ MARTÍNEZ, F. (2005): «El Plan de Ordenación del Territorio de Andalucía». Cuadernos Geográficos de la Universidad de Granada, $\mathrm{n}^{\circ} 38,277-289$.

RODRÍGUEZ MARTÍNEZ, F. y SÁNCHEZ ESCOLANO, L.M. (2010): «La planificación territorial y el sistema urbano de Andalucía. Notas para una reflexión desde la Geografía». Cuadernos Geográficos, nº 47, 223-245.

RUIZ ORTEGA, J. L. (2004): «Patrimonio y desarrollo local en Andalucía». Boletín de la Asociación de Geógrafos Españoles, $\mathrm{n}^{\circ} 38,101-114$.

SERRANO AGUILAR, J. (2010): «La protección del dominio público hidráulico en Andalucía». Tecno-Ambiente: Revista profesional de tecnología y equipamiento en ingeniería, $\mathrm{n}^{\mathrm{o}} 204,30-36$.

SILVA PÉREZ, R. (2008): «Hacia una valoración patrimonial de la agricultura». Scripta Nova. Revista electrónica de Geografía y Ciencias Sociales. Vol. XII, nº 275.

- (2009): «Agricultura, paisaje y patrimonio territorial. Los paisajes de la agricultura vistos como patrimonio». Boletín de la A.G.E., nº 49, 309-334.

SILVA PÉREZ, R. y FERNÁNDEZ SALINAS, V. (2008): «El patrimonio y el territorio como activos para el desarrollo desde la perspectiva del ocio y el turismo». Investigaciones Geográficas, nº 46, 69-88.

TROITIÑO, M.A. (1998): «Patrimonio arquitectónico, cultura y territorio». Ciudades: Revista del Instituto de Urbanística de la Universidad de Valladolid, n 4, 95-104.

VILLARROYA ALDEA, C. (2004): «La delimitación del dominio público hidráulico y el Proyecto LINDE». Ambienta, $\mathrm{n}^{\circ}$ 36, 50-58.

ZOIDO NARANJO, F. (2002): «Andalucía, cohesión y diversidad territorial». Scripta Nova. Revista electrónica de Geografía y Ciencias Sociales, vol. VI, nº 128. Diponible en: http://www.ub.edu/geocrit/sn/sn-128.htm

- (2011): «Ordenación del Territorio en Andalucía. Reflexión personal». Cuadernos Geográficos de la Universidad de Granada, n 47, 189-211.

ZOIDO NARANJO, F. y VENEGAS MORENO, C. (coords.) (2002): Paisaje y Ordenación del Territorio. Sevilla, Junta de Andalucía. Consejería de Obras Públicas y Transportes. 
